\title{
Pluriatividade no meio rural: flexibilização e precarização do trabalho na agricultura familiar
}

Pluriactivity in rural areas:

flexibility and precariousness of work in family farming

Rosangela Werlang*

Jussara Maria Rosa Mendes**

\begin{abstract}
Resumo - Este artigo é fruto de pesquisa teórica realizada no âmbito do Núcleo de Estudos e Pesquisa em Saúde e Trabalho (Nest/UFRGS) e trata da saúde do trabalhador no meio rural. Neste sentido, aborda os processos de modernização nas áreas rurais, articulados às transformações no trabalho, assim como às implicações de tais modificações na vida do pequeno agricultor. Além disso, aponta a investida do capital para que se consolide o fim da pequena agricultura tradicional, seja por meio da articulação com a indústria, seja por meio da pluriatividade, expressão contemporânea da flexibilização e, ademais, da precarização do trabalho. Destarte, este estudo objetiva apresentar a pluriatividade e a articulação com a indústria enquanto expressões da transformação do trabalho no meio rural, assim como a possibilidade contígua da destruição da agricultura familiar.

Palavras chave: áreas rurais; precarização; pluriatividade; trabalho; agricultura familiar.
\end{abstract}

\begin{abstract}
This article is the result of a theoretical research carried out by the Núcleo de Estudos e Pesquisa em Saúde e Trabalho (NEST/ UFRGS), which dealt with the health of rural workers. In this sense, it deals with the processes of modernization in the rural areas in conjunctions with the transformations in work, as well as the implications of these changes in peasant life. In this regard, it points to the capital invested to consolidate the end of the family farming, either through cooperation with the industry, or through pluriactivity, a contemporary form of flexibility, and, moreover, of the precariousness of work in rural areas. Thus, the objective was to present pluriactivity and the
\end{abstract}

\footnotetext{
* Pós-doutorado em Psicologia Social e Institucional (UFRGS/CNPq/PDJ). Pesquisadora Visitante (UFRGS/CNPq). Membro do Núcleo de Estudos em Saúde do Trabalhador (NEST). Professora convidada do curso de Especialização em Ética e Educação em Direitos Humanos da Faculdade de Educação (FACED/UFRGS) e da Especialização em Saúde do Trabalhador, do Instituto de Psicologia (PPGPSI/UFRGS). Correspondência: Rua Anita Garibaldi, 372/302, Bairro Mont'Serrat, Porto Alegre/RS. CEP: 90450-000. Email: <rosangelawerlang@gmail.com>.

** Pós-doutorado em Serviço Social pela Universität Kassel (Alemanha - 2010). Professora do Programa de Pós-Graduação em Psicologia Social e Institucional/UFRGS e professora adjunta do curso de Serviço Social da UFRGS. Colaboradora do Programa de Pós-graduação em Serviço Social da PUC-RS. Coordenadora do Núcleo de Estudos em Saúde e Trabalho - NEST/UFRGS. Consultora do MS/COSAT e do Conselho Nacional de Desenvolvimento Científico e Tecnológico. Correspondência: Rua Ramiro Barcelos, 2777, Anexo 1 da Saúde, sala 318, Bairro Santana, Porto Alegre, Rio Grande do Sul. CEP 90035-007.Email: <jussara.mendes@ufgrs.edu.br>.
} 
articulation between rural work and industry as expressions of the transformation and precariousness of work in rural areas, as well as the contiguous possibility of the destruction of family farming.

Keywords: rural areas; precariousness; pluriactivity; work; family farming.

\section{Introdução}

Este artigo trata da flexibilização e da precarização do trabalho na agricultura familiar. $\mathrm{O}$ avanço capitalista, ensejado pela modernização que adentra o campo, tem conduzido a novas formas de trabalho e de vida no meio rural, afetando sobremaneira os pequenos agricultores que vivem da agricultura familiar nas pequenas propriedades rurais. Destarte, a articulação ou integração com a indústria seria uma das formas por meio da qual se expressa o avanço do capital no campo. Outra forma seria a inserção de atividades não necessariamente agrícolas no seio das famílias dos pequenos agricultores, a chamada pluriatividade, fazendo com que o rural e o pequeno agricultor se distanciem de sua característica principal, qual seja, a de produzir alimentos para o seu sustento, tendendo por fim ao assalariamento.

É inegável a contradição que se instala neste espaço de vida e trabalho, que expressa o ocaso da pequena agricultura familiar. Esta, para sobreviver, flexibiliza-se e precariza as relações de trabalho, alterando, pouco a pouco, o ser e o fazer do pequeno agricultor. Assim, este estudo, fruto de pesquisa teórica realizada no Núcleo de Estudo e Pesquisa em Saúde e Trabalho (Nest) do curso de Serviço Social da Universidade Federal do Rio Grande do Sul (UFRGS), com apoio do Conselho Nacional de Desenvolvimento Científico e Tecnológico (CNPq), objetivou refletir sobre o ocaso da pequena agricultura familiar, via mecanismos conexos ao capital, quais sejam, a articulação com a indústria e, especialmente, a pluriatividade. Desse modo, este artigo encontra-se estruturado em duas partes: a primeira, que aborda o processo de modernização da agricultura, e a que trata das formas de flexibilização e precarização do trabalho no meio rural enquanto expressões da investida do capital contra a pequena agricultura familiar. 


\section{O processo de modernização da agricultura: o ocaso do pequeno agricultor}

O período que se iniciou após a década de 1960 foi marcado pela expansão das atividades econômicas no Brasil, assinalando também a intensificação da modernização do espaço agrário no país. Tal intensificação esteve associada a políticas de crédito agrícola que, por sua vez, aliavamse ao desenvolvimento das primeiras indústrias de insumos agrícolas. Todavia, esse ciclo de crescimento passou a sofrer instabilidades quando os preços internacionais e o crédito para investimentos, alimentados pelo governo, foram reduzidos. Para os agricultores que haviam investido no cultivo de grãos, a crise foi incansável, já que houve redução de recursos para os financiamentos agrícolas. Parte dos agricultores que estavam organizados e capitalizados deu continuidade ao caminho rumo a uma agricultura "moderna e tecnificada" (ANDREATTA, 2009, p. 15). Por sua vez, os pequenos agricultores vinculados à agricultura familiar não tiveram tanta sorte. Sem os recursos disponíveis e sem as garantias exigidas para a obtenção de financiamentos, os pequenos agricultores ficaram praticamente à margem de todo o processo que serviu àqueles bem estabelecidos e capitalizados.

Pode-se assinalar que o processo de modernização na agricultura pertinente à segunda metade do século XX delineia-se por meio de três mudanças importantes: a mudança na base técnica da produção, a mudança na composição das culturas e a mudança na concentração fundiária e na utilização das terras (SOUZA FILHO, 1994). Com relação à mudança na base técnica, houve a "tecnificação" do espaço agrário, notadamente através de dois elementos: a quimificação e a mecanização. A quimificação se deu principalmente através do uso de fertilizantes e defensivos químicos. Já a mecanização se deu, especialmente, por meio da utilização dos tratores nas atividades agropecuárias. O crescimento do uso de fertilizantes químicos se estabeleceu de forma imponente, assim como a utilização dos defensivos químicos. São inseticidas, fungicidas e herbicidas que tiveram incremento em sua utilização, aliados ao uso de tratores nas áreas dedicadas à lavoura. Neste sentido, com relação às modificações da base técnica da agricultura, pode-se dizer que o processo de tecnificação baseou-se, resumidamente, no uso de insumos químicos e na tratorização. Podem-se destacar, além disso, as inovações por produto, como as sementes selecionadas e o uso de técnicas específicas para conservação do solo e de irrigação.

A modificação na composição das culturas também é elemento importante nesta análise. A partir dos anos 1970, há um incremento muito pequeno ou mesmo negativo dos produtos tecnologicamente tradicionais ou destinados ao mercado interno. Por outro lado, crescem as culturas de exportação, como a soja, com forte articulação com a agroindústria (SOUZA FILHO, 1994). Destarte, houve a expansão dessa cultura aliada a toda uma 


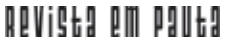

\} PLURIATIVIDADE NO MEIO RURAL - WERLANG, R.; MENDES, J. M. R. \}

DOI: $10.12957 /$ REP.2016.27857

política comercial e de incentivos, especialmente àqueles atrelados aos preços internacionais que estimulavam o plantio de produtos destinados à exportação.

Com relação às modificações do espaço agrário articuladas à concentração fundiária e ao uso da terra, percebe-se um aumento do grau de concentração da propriedade da terra, mesmo considerando-se que, historicamente, a estrutura fundiária brasileira sempre tenha sido bastante concentrada. Há, assim, uma espécie de reconcentração fundiária, impedindo o acesso à terra para a produção agrícola de boa parte da população.

No entanto, há que se considerar, também, o processo de reestruturação das relações estabelecidas no processo produtivo rural, especialmente dos pequenos produtores, a partir das implicações estabelecidas por meio da produção agroindustrial (TEDESCO, 1994). A tendência à modernização aprofundou as relações entre indústria e agricultura, na tentativa de transformar a produção agrícola em um processo de cunho industrial, promovendo a divisão social do trabalho numa complexidade de relações sociais de produção entre o rural e o urbano, desconsiderando, neste interim, fatores históricos e culturais de produção e de contato com a terra, atinente aos pequenos agricultores. As relações sociais estabelecidas no processo de integração entre os pequenos agricultores e a indústria, sobretudo no caso da produção integrada de aves e suínos, seria parte inerente da estratégia modernizante da agricultura, objetivando diversificar a produção e promover a acumulação do capital industrial (TEDESCO, 1994).

A integração da agricultura familiar à indústria se apresentará como uma das formas do desenvolvimento do capital na agricultura. Assim, pode-se dizer que a substituição das atividades agrícolas ditas "naturais" vem sendo aos poucos ocupada por atividades integradas à indústria. Esta, cada vez mais, intensifica a divisão do trabalho e especializa a produção agrícola. Para além do vínculo da agricultura com a indústria, esta última também vai se especializando. O capitalismo, quando entra no campo, faz com que se aprofunde a divisão do trabalho e, além disso, com que o camponês ou o pequeno agricultor tenham a sua economia natural destruída. A partir deste ponto, podem ser criadas as bases para o desenvolvimento do capitalismo onde este não se encontre ainda implantado. Ao destruir as bases da economia natural, criam-se as condições necessárias para que o capitalismo se expanda. Esta tese é sustentada por Marx (1980, p. 404), que afirmar que:

[...] o fundamental de toda divisão do trabalho desenvolvida e processada através da troca de mercadorias é a separação entre cidade e campo. Pode-se dizer que toda história econômica da sociedade se resume na dinâmica dessa antítese [...] o modo de produção capitalista completa a ruptura dos laços primitivos que no começo uniam a agricultura e a manufatura. Mas, ao mesmo tempo cria as condições materiais para uma síntese nova, superior, para a união da agricultura 
e da indústria, na base das estruturas que se desenvolveram em mútua oposição.

Para Marx (1980), a história antiga seria a história das cidades; todavia, das cidades que tiveram a sua base econômica assentada na agricultura e na propriedade rural. Já a história asiática seria uma espécie de unidade indiferente entre cidade e campo. No Medievo, por sua vez, a área rural seria o cenário da história cujo desenvolvimento posterior darse-ia através da discrepância entre cidade e campo; "a história moderna seria, então, o processo de urbanização da área rural e não a ruralização da cidade" (MARX, 1986, p. 74-75).

O processo de "industrialização do campo", ou mesmo de "urbanização da área rural", somente estaria completo quando a indústria se mudasse para o campo. Entretanto, observa-se a tendência de o próprio campo se transformar em indústria, em fábrica, com o advento da agroindústria, do "agronegócio". Desse modo, a agricultura como ramo natural vai tendendo à transformação, aspirando converter-se, cada vez mais, em um dos ramos da indústria.

A agricultura modifica-se com uma ênfase industrial, constituindose em um setor que se encontra subordinado ao capital. É neste sentido que se pode asseverar que "o espaço rural tem sofrido fortes impactos", causados por mudanças estruturais na economia e relacionados, em boa parte, aos processos de integração econômica. Entre tais processos encontrase a queda nas condições de sustentabilidade das unidades de produção agrária, decorrente da redução de sua sustentabilidade, na qual o vínculo com a indústria seria a pretensa alternativa à sustentabilidade das pequenas propriedades agrícolas (FERNANDES FILHO; CAMPOS, 2003).

Como já apontado por Marx, o processo de destruição da economia natural camponesa inicia-se com a revolução agrícola, consumandose com o desenvolvimento capitalista de produção. Assim, a destruição desta economia levou à separação entre cidade e campo, ficando o campo com o desenvolvimento e a prática das atividades relativas à agricultura. Ocorre, portanto, a separação entre manufatura e agricultura, em que a primeira das atividades passa a ser exercida em outro espaço: aquele destinado às atividades ditas "urbanas", relativas à cidade. Essa separação teria se iniciado no período manufatureiro, sendo completada no modo de produção capitalista. Desta maneira, o desenvolvimento do capitalismo no campo levou também à destruição da indústria rural. Houve um deslocamento das atividades de manufatura, antes realizadas nas unidades de produção agrícolas, sendo que estas passaram a ser desenvolvidas nas cidades.

Contudo, a distinção entre campo e cidade fica, contemporaneamente, cada vez mais difícil de ser caracterizada, como atesta Graziano da Silva (2002, p. 2): “Está cada vez mais difícil delimitar o que é rural e o que 


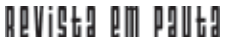

\} PLURIATIVIDADE NO MEIO RURAL - WERLANG, R.; MENDES, J. M. R. \}

DOI: $10.12957 /$ REP.2016.27857

é urbano". Do ponto de vista espacial e da atividade econômica desenvolvida, cada vez menos os espaços rural e urbano se distinguem. Hodiernamente, as cidades já não podem mais ser identificadas apenas com a atividade industrial, da mesma forma que o campo não pode mais ser identificado somente com as atividades relacionadas à agricultura e à pecuária.

Lênin (1980) afirma, por sua vez, que o indicador essencial do capitalismo na agricultura seria o trabalho assalariado e, sendo o maior indicador, apontaria para o desenvolvimento do capitalismo no campo. $\mathrm{Na}$ análise empreendida acerca da agricultura nos Estados Unidos, afirma o autor que, em se confrontando os dados de uma mesma natureza e de uma mesma época relativos à indústria e à agricultura, esta última aparecerá sempre com um atraso significativo se comparada à primeira. Ademais, ele observou uma vasta possibilidade de eliminação da pequena produção, tanto na agricultura quanto na indústria. Para o autor, os pequenos agricultores, "independentes e ainda cheios de ingênuas ilusões sobre a possibilidade de viverem do trabalho de suas próprias mãos" (LÊNIN, 1980, p. 62), parecem, de fato, em estar vias de aniquilamento. Lênin (1980) con-cluirá seu estudo afirmando que:

a) Na agricultura, o trabalho manual predomina ainda sobre as máquinas mais do que na indústria; no entanto, está em constante avanço, melhorando as técnicas de cultivo, ampliando as escalas de exploração e tornando-as cada vez mais capitalistas;

b) $\mathrm{O}$ indicador essencial do desenvolvimento do capitalismo na agricultura é o assalariamento, bem como o emprego de máquinas em todos os ramos da agricultura;

c) O aumento do número de trabalhadores assalariados tenderá a superar o da população rural;

d) A eliminação da pequena produção pela grande produção avança na agricultura, mas essa eliminação é minimizada e a situação dos pequenos agricultores é "embelezada", já que os investigadores, não raro, classificam as explorações segundo a superfície, escondendo a sua intensidade;

e) O capitalismo não se expande apenas pela aceleração do desenvolvimento das explorações de grande extensão nas regiões de agricultura extensiva, mas também pela criação de explorações maiores quanto ao volume de sua produção, de caráter capitalista mais acentuado e em lotes de terra de menor dimensão nas regiões de agricultura intensiva;

f) Enfim, a concentração da produção nas grandes explorações seria efetivamente mais forte, e a eliminação da pequena produção seria efetivamente mais profunda e progressiva do que os dados indicam, ou seja, a expropriação da pequena agricultura prosseguiria. 


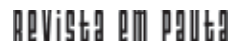

\} PLURIATIVIDADE NO MEIO RURAL - WERLANG, R.; MENDES, J. M. R. \}

DOI: $10.12957 /$ REP.2016.27857

Em obra diversa, Lênin (1985) também aborda a questão relativa ao fim do campesinato na sua articulação com o avanço do capitalismo na Rússia. Para o autor, haveria uma espécie de diferenciação social dos camponeses, apontando à decomposição destes em patrões e operários agrícolas, sendo estes últimos a maioria. O processo de desintegração do campesinato seria, desta forma, um processo irreversível por meio do avanço capitalista.

Utilizando-se de diferentes dados estatísticos, o autor antevê o processo de expansão capitalista rumo ao campo. Este traria consigo a transformação do camponês, que se converteria em empresário rural ou, ainda, em trabalhador assalariado. O camponês vinculado às atividades da terra e produzindo para a sua sobrevivência e a da família estaria em vias de extinção, como já aludido anteriormente. Todavia, cabe ressaltar que o camponês tenderia a ficar subordinado ao mercado tanto no que condiz à sua sobrevivência em termos de consumo, quanto em termos da atividade agrícola propriamente dita. Tal transformação serviria bem ao desenvolvimento do capitalismo na medida em que seriam criados novos espaços para este se expandir, ampliando as fronteiras já abarcadas pelas cidades. É assim que o campesinato, considerado por Lênin (1985) como "antigo" e "tradicional", deixará de existir, sendo substituído por novos tipos de população rural, que entrariam no círculo de uma sociedade dominada pela economia mercantil e pela produção de caráter capitalista.

O advento do capitalismo e sua inserção no campo, notadamente nos países desenvolvidos, trouxe consigo algumas características específicas, quais sejam: o desmonte das atividades produtivas em função da possibilidade de externalização de várias outras atividades, que antes tinham que ser realizadas no campo, por meio da contratação de serviços externos; a especialização produtiva crescente, permitindo o aparecimento de novos produtos e de mercados secundários; a formação de redes, vinculando fornecedores de insumos, prestadores de serviço, agricultores, agroindústrias e empresas de distribuição comercial; o crescimento do emprego qualificado no meio rural, notadamente das profissões técnicas e administrativas de conteúdo tipicamente urbano, como motoristas, mecânicos, digitadores e profissionais liberais vinculados às atividades rurais não agrícolas; e melhorias da infraestrutura social e de lazer, com maior facilidade no transporte e meios de comunicação, possibilitando, com isso, maior acesso aos bens públicos (ABRAMOVAY et al., 2004).

Contudo, há também altos níveis de pobreza e miséria nas regiões rurais, uma vez que a realidade dos países centrais ou desenvolvidos difere daquela vivida nos países subdesenvolvidos ou periféricos. Hobsbawm (2000, p. 284) assevera que "a mudança social mais impressionante e de mais longo alcance da segunda metade deste século, e que nos isola para sempre do mundo do passado, é a morte do campesinato". Por morte do campesinato o autor compreende a drástica mudança social que se está ainda atravessando, com a redução da população vinculada ao trabalho 


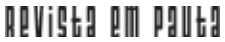

\} PLURIATIVIDADE NO MEIO RURAL - WERLANG, R.; MENDES, J. M. R. \}

DOI: $10.12957 /$ REP.2016.27857

agrícola. Segundo o autor, no início da década de 1980, menos de três em cada cem britânicos ou belgas trabalhavam na agricultura. A população agrícola nos Estados Unidos também teria caído para essa mesma proporção.

Aliado às inovações tecnológicas, tanto em termos de maquinaria como em termos de produtos químicos de combate às pragas, a agricultura passa, cada vez mais, a não necessitar da mão de obra dos inúmeros trabalhadores que eram, até então, responsáveis pela colheita das diferentes safras agrícolas. $\mathrm{O}$ aumento, em termos de produtividade, resultante da "Revolução Verde", tem sido tão importante que vem sobrepujando outros setores da economia, como a indústria e mesmo os serviços (MAZOYER, 2004). Como consequência, os preços dos produtos agrícolas têm aumentado de forma muito mais lenta do que outros produtos.

Como visto anteriormente, nos anos 1960 e 1970, muitos países considerados desenvolvidos viveram a chamada Revolução Verde, cujo objetivo centrava-se no plantio de produtos agrícolas voltados ao mercado exportador, como o trigo, a soja e o milho, inclusive com a utilização de novas linhagens desses produtos, garantindo boa produtividade (CAVALCANTE, 2004). A produção aumentou, mas não reduziu a fome e a desnutrição, percebendo-se que a chamada revolução não estabelecia vínculo algum com as necessidades de boa parte da população, que possui, ainda, necessidades de consumo para própria sobrevivência, desenvolvimento e reprodução da vida.

Nos Estados Unidos, as sementes melhoradas ou geneticamente modificadas, combinadas com fertilizantes específicos, permitiram colheitas maiores e fizeram baixar os preços dos produtos agrícolas. Não obstante, tal produtividade foi acompanhada pela alta nos custos da produção agrícola, diminuindo as margens de lucro. Essa agenda é também defendida por todos aqueles que possuem interesse nessa questão, como a Organização Mundial do Comércio (OMC), para quem a agricultura, nas diferentes rodadas de negociação, vem sendo vista como um dos grandes espaços para acesso aos mercados mundiais. Tudo isso devido aos excedentes de produção da agricultura capitalista que, para sobreviver, necessita cada vez mais arruinar a pequena agricultura camponesa e controlar, de modo monopolizado e padronizado, o uso de sementes e agrotóxicos de toda ordem (CAVALCANTE, 2004). Como bem afirma Oliveira (2004, p. 226), o mercado é implacável e cada vez menos se regula pelo nacional: "Mundializado él mundializa al nacional". Destrói-se, desta maneira, as suas bases, lançando o país nas tramas da rede capitalista mundial.

É neste contexto que a agricultura familiar passa por metamorfoses que engendram novos processos agrários, novas relações de trabalho e novas estratégias de reprodução. São estabelecidas relações de assalariamento produzidas pela aproximação "[...] do pequeno agricultor com a indústria e também pelo advento da sojicultura" (SCHNEIDER, 2004, p. 86), vetores da modernização capitalista. A emergência dos novos assala- 
riados ou "colonos-operários" decompõe a forma de organização da agricultura familiar, anunciando que já não se faz o trabalho no meio rural da mesma maneira. Dessa forma, pode-se induzir que o rural já não é mais sinônimo de essencialmente agrícola. Esse "novo rural" que surge pressupõe

[...] uma agropecuária moderna, ligada à agroindústria que vem sendo chamada de agribusiness brasileiro; um conjunto de atividades de subsistência que gira em torno da agricultura rudimentar e da criação de pequenos animais e que visa manter uma determinada população no campo e um exército de trabalhadores rurais sem-terra, sem emprego fixo, sem qualificação e que foram excluídos pelo mesmo processo de modernização que gerou o agribusiness; um conjunto de atividades não-agrícolas ligadas à moradia, lazer e várias atividades industriais e de prestação de serviços e, ainda, todo um conjunto de atividades agropecuárias localizadas em 'nichos' específicos de mercado. (GRAZIANO DA SILVA, 2002, p. 67 - grifos originais).

Esta é a situação da agricultura brasileira que, de maneira geral, vive um processo de "desruralização". Cada vez mais o pequeno agricultor encontra-se despojado dos laços que o ligam à terra e aos seus meios de produção. Trata-se de uma expropriação lenta e vil (MACHADO; CASALINHO, 2010). Esse processo, chamado acima de desruralização, relacionase também a um movimento de desconcentração da produção industrial, iniciado por volta dos anos 1970 (SANTOS; SILVEIRA, 2004). Além disso, entre os anos 1970 e 1980 houve um crescimento de cerca de $184 \%$ dos estabelecimentos industriais no Brasil. No entanto, a partir dos anos 1980 houve um decréscimo no número de estabelecimentos industriais derivado, em boa medida, do processo de concentração da propriedade industrial, que avança. Há um movimento de desconcentração das indústrias, que passam a exercer suas atividades fora dos grandes centros urbanos.

Na contemporaneidade, os pequenos agricultores ou camponeses têm sido duramente sacrificados, seja pela modificação na base técnica de suas atividades, seja através da utilização massiva da química nos cultivos, do uso de máquinas e equipamentos e mesmo da diversificação das culturas. Desse modo, atende-se às demandas internacionais, não raras vezes associadas às políticas e incentivos de caráter nacional e/ou internacional. Em verdade, pode-se dizer que par i passo a essas alterações o conjunto do conceito da agricultura tem mudado. De um modo integral de vida, passa a constituir-se em um modo integral de obtenção de lucros.

La agricultura capitalista, representada por una clase de nuevos campesinos ricos y hasta por latifundistas modernizados, o por grandes extensiones explotadas por las transnacionales del agrobusiness, se apresta a apoderarse de la agricultura campesina. (SWAMINATHAN, 2005, p. 28 - grifo original) 


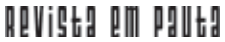

\} PLURIATIVIDADE NO MEIO RURAL - WERLANG, R.; MENDES, J. M. R. \}

DOI: $10.12957 /$ REP.2016.27857

O mundo rural ou agrário já se encontra tecido e emaranhado pela atuação das empresas, corporações e conglomerados industriais. De acordo com lanni (1994), são núcleos ativos e predominantes que articulam as atividades produtivas e os mercados, as geopolíticas mercantis, os marketings e as modalidades de produtos, fazendo com que o rural seja subsumido ao grande capital. Cabe ainda ressaltar as atividades das transnacionais, que modificam a utilização do solo e a orientação das atividades agrícolas, gerando, inclusive, tendências no emprego capitalista da terra agrícola no que se refere à produção de proteínas, substituindo, não raras vezes, as dietas tradicionais da população em geral. Assim, em quase todos os setores agropecuários está a ocorrer a racionalização dos processos produtivos, de organização social e técnica do trabalho, de modo a acelerar a produtividade e a ampliar as condições de produção de excedentes, de lucro, de mais-valia (IANNI, 1994). Todavia, ainda subsiste a pequena produção, a pequena propriedade rural de tipo familiar.

Para ilustrar a violência dos procedimentos capitalistas, cita-se Houtart (2005), que, ao analisar a situação dos pequenos agricultores dedicados ao cultivo do arroz no Sri Lanka, apresenta circunstância bastante complexa. O autor explica que, há mais de 2.500 anos, o Sri Lanka foi uma sociedade que girou em torno do cultivo do arroz, e este representava $75 \%$ do consumo de cereais.

Cerca de $80 \%$ de los pequeños productores agrícolas cultivan arroz. La sociedad se forjó por el control del agua como factor clave de la producción agrícola básica y no por la propiedad del suelo como en Europa. El poder político se erigió en torno del dominio de la irrigación desde la época de los pequeños reinos del primero milenio antes de J. C. hasta la unificación de la isla, 500 años antes de nuestra era, bajo un poder único capaz de organizar un sistema integrado de irrigación. (HOUTART, 2005, p. 55).

O que aconteceu foi que, depois da independência, os primeiros governos ainda mantiveram a propriedade da terra, que era coletiva, e desenvolveram políticas de apoio aos pequenos agricultores. No entanto, a partir de 1977 o governo passou a orientar a economia de acordo com as políticas desenhadas pelo Consenso de Washington, ou seja, passou-se a produzir para exportação, a liberalizar os mercados, a efetuar trabalhos de infraestrutura para atrair investimentos estrangeiros no país e, por fim, a desmantelar os sistemas de proteção econômica e social. Neste contexto, o país ingressa em uma conjuntura onde predomina a desigualdade, e a vida no meio rural vai se tornando inviável. Há um decréscimo no preço dos produtos agrícolas, a renda familiar é reduzida, a pobreza avança e os camponeses entram em estado de desespero.

Entre as várias reformas realizadas com o aval do Banco Mundial naquele país, encontra-se a privatização. Seria necessário acelerar os proces- 


\section{hevistg an pguttg}

\} PLURIATIVIDADE NO MEIO RURAL - WERLANG, R.; MENDES, J. M. R. \}

DOI: $10.12957 /$ REP.2016.27857

sos de privatização, introduzir uma maior flexibilidade no trabalho, outorgar aos pequenos proprietários agrícolas títulos de propriedade, já que estes ainda não contavam com tal documento, eliminar todos os obstáculos para a aquisição de terras por estrangeiros e, finalmente, suprimir as proteções e introduzir o setor privado na educação e na saúde (HOUTART, 2005). Semelhante situação também é percebida na Índia, onde cada vez mais o camponês se encontra depauperado e marginalizado. Como afirma Swaminathan (2005, p. 27) ao abordar os diversos desafios que se colocam à questão da agricultura, o mais importante estaria em "[...] la forma de salvar nuestra agricultura y a nuestro campesinato de la total destrucción".

Hardt e Negri (2004), por sua vez, compactuam com a ideia do fim ou do crepúsculo do mundo camponês. Para compreender a categoria de camponês, os autores afirmam que este seria, primordialmente, um conceito econômico que designa uma posição específica dentro das relações de produção e de intercâmbio. Em uma primeira aproximação, pode-se definir os camponeses como sendo aqueles indivíduos que trabalham a terra, produzem especialmente para o autoconsumo, estão parcialmente integrados e subordinados dentro de um sistema econômico mais amplo e são proprietários de ou têm acesso à terra. Os pequenos proprietários agrícolas ou pequenos agricultores tenderiam ao desaparecimento, pois as pequenas propriedades seriam de forma constante alvo de arrebatamento por parte dos grandes latifúndios.

Como já referido, tal categoria de trabalhadores parece estar em vias de extinção, vítimas que são das estratégias desenhadas por parte dos governos nacionais e estrangeiros, das corporações agrárias multinacionais e transnacionais, do Banco Mundial e do Fundo Monetário Internacional, que visam à modernização capitalista e à integração econômica global. Essa modernização traz uma forte tendência à especialização agrícola e, segundo essa ideologia econômica, a agricultura de subsistência a cargo dos pequenos proprietários representaria o atraso e a ineficácia do ponto de vista econômico, não apenas por suas limitações tecnológicas, mas especialmente por suas relações de troca (WOLF, 1971).

Deste modo, a produção familiar não pode ser compreendida fora do quadro de formação e organização capitalista, fora do conjunto em que se encontra circunscrita (ARAÚJO, 2002). Quando interligada a uma formação capitalista, a forma de produção familiar se encontra esvaziada de conteúdo, sendo dominada pelo capital e gerando consequências para os pequenos produtores: estes são despojados da propriedade real do solo, ficando apenas com a propriedade formal do mesmo (AMIN; VERGOPOULUS, 1977).

A pequena produção familiar ou camponesa, do ponto de vista econômico, pode ser definida, sobretudo, por quatro características que aqui se ressaltam: acesso estável à terra, seja em forma de propriedade, seja mediante algum tipo de usufruto; trabalho predominantemente familiar, o 


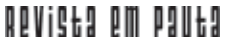

\} PLURIATIVIDADE NO MEIO RURAL - WERLANG, R.; MENDES, J. M. R. \}

DOI: $10.12957 /$ REP.2016.27857

que não exclui, em certos casos, o recurso a uma força de trabalho adicional, externa ao núcleo familiar; economia fundamentalmente de subsistência, sem excluir, por isto, a vinculação eventual ou permanente com o mercado; e, por fim, certo grau de autonomia na gestão das atividades agrícolas, ou seja, nas decisões essenciais sobre o que plantar e de que maneira, como dispor do excedente etc. (CARDOSO, 2002).

Isto posto, pode-se dizer que as mutações pelas quais passa o trabalho situam-se, na visão de Hardt (2003, p. 148), "[...] em uma sucessão de paradigmas econômicos dominantes desde a Idade Média", e que implicaram, primeiramente, na agricultura e na extração de matérias-primas como dominantes na economia. Posteriormente, conduziram a indústria para uma posição preponderante, principalmente no que se refere à produção de bens duráveis e, por fim, no paradigma atual, no qual predomina a prestação de serviços e o processamento de informações, que são considerados como a essência da produção econômica. Passa-se então, segundo o autor, de uma produção primária para uma secundária, e desta para uma produção terciária. Dessa maneira, os postos de trabalho na agricultura, e mesmo na extração ou mineração, deslocam-se para a indústria, sinalizando para um período conhecido como "período de modernização econômica" (HARDT, 2003, p. 156).

Após isso, nos processos de "pós-modernização ou informatização", há um deslocamento dos postos de trabalho da indústria para o setor de serviços. Todavia, a passagem para essa última fase transformou a qualidade e a natureza do trabalho e dos seus processos. Passa-se de um modelo fordista para um modelo toyotista, com o incremento dos setores de serviço na economia, e isso não resulta, ao final, em bens materiais duráveis; ocorre o chamado "trabalho imaterial" (HARDT, 2003, p. 158), ou seja, um trabalho que produz um bem que é imaterial, como, por exemplo, serviços, conhecimento ou comunicação. Esse trabalho "produce bienes inmateriales tales como información, conocimientos, ideas, imágenes, relaciones y afectos" (HARDT; NEGRI, 2004, p. 92-93). Assim, as formas imateriais tendem a precarizar ainda mais as relações de trabalho, por exemplo, fazendo com que os horários de trabalho não sejam mais tão distintos e se trabalhe cada vez mais, não havendo mais contratos estáveis.

As transformações no mundo do trabalho, por certo, modificam a maneira de ser e de fazer das pessoas. Como proceder diante do novo, de uma nova configuração, de uma nova articulação, na qual ser/fazer não são mais os mesmos? De acordo com Herrera Flores (2005, p. 148):

[...] en el proceso cultural que se despliega en Occidente desde el siglo XVI hasta nuestros días, el trabajo- entendido como la posibilidad de hacer tanto en el ámbito público como en el privado- ha representado no sólo la forma de acción a partir de la cual se producen mercancías o se prestan servicios, sino también el modelo hegemónico de subjetivación humana. Trabajar o hacer otorgan, en nues- 
tras coordenadas culturales, identidad, sentido de pertenencia y de utilidad social. De ahí los problemas psicológicos que arrastran las situaciones de desempleo o de empleo precario y, asimismo, la consideración de no-trabajo (no-hacer) que, para el capitalismo [...] supone la realización de las tareas llevadas a cabo en el ámbito privado $[\ldots]$.

Destarte, o trabalho "no solo crea el valor objetivo o económico, sino también la sensación de plenitud psicológica individual" (HERRERA FLORES, 2005, p. 149), apondo valor a qualquer produto surgido da atividade humana. Cabe ressaltar que as transformações no trabalho hoje se apresentam como transformações que se apropriam não mais somente da força de trabalho, mas de toda a capacidade produtiva humana, incluindo o pensar. Enfim, as transformações são abundantes e impactam a vida dos trabalhadores rurais.

\section{A pluriatividade: flexibilização do trabalho no meio rural}

No mundo rural, as transformações acerca do trabalho afetam também a "ruralidade" (ABRAMOVAY, 2003, p. 25), ou seja, alteram o contato dos habitantes locais com o meio natural. Cabe destacar que, como parte das transformações que assolam o campo, fora aquelas já destacadas, começam a despontar atividades não necessariamente agrícolas no espaço rural, matizando com novas cores o cenário das transformações. Emerge, assim, a pluriatividade, ou a part-time farming, que deteriora a organização do espaço rural, mesclando o rural com o urbano de forma inigualável. Ao mesmo tempo em que as atividades não agrícolas se constituem em novas fontes de renda para as famílias, elas devastam o rural naquilo que foi sempre a sua característica fundante: o trabalho com a terra, visando à produção de alimentos. Estimuladas pelo desenvolvimento das telecomunicações e das demais tecnologias, novas indústrias e serviços auxiliares de produção têm marcado presença também no campo. Assim, o campo passa a ser local da "pluriatividade", ou seja, de atividades múltiplas que não são necessariamente aquelas vinculadas à agricultura ou à pecuária.

O debate acerca da pluriatividade no país teve início por meio do trabalho de Sacco dos Anjos (2001), quando este atestou que em apenas um conceito poderiam ser condensadas duas outras noções fundamentais, quais sejam: a de agricultura de tempo parcial e a diversificação econômica e produtiva. Todavia, para o autor, no âmbito acadêmico brasileiro, tal noção ganha importância apenas na metade dos anos 1980, enquanto que na Europa, notadamente na França, era utilizado desde os anos 1970. Até então, as alusões ao fenômeno de desenvolvimento de atividades não necessariamente agrícolas no meio rural eram chamadas de agricultura de tempo parcial (part time farming), procurando dar conta dos processos de 
industrialização e dos processos a esta correlatos, que avançavam sobre as regiões rurais.

O uso do termo 'pluriatividade' marca uma profunda transição tanto do ponto de vista do marco político e institucional e do modo como até então tal noção vinha sendo valorada, como também no plano da percepção levada a cabo pelos cientistas sociais em seus estudos sobre a evolução das estruturas agrárias contem-porâneas. [...] O certo é que praticamente em todos os idiomas há palavras para designar esta figura, amplamente identificada no cenário social europeu pós-Segunda Guerra Mundial, tais como: campesino obrero, worker peasant, ouvrier-paysan, arbeiterbauer, operai-contadini, camponês operário etc, destacando-se, neste plano, o cres-cente grau de unificação entre os mercados de trabalho urbano e rural. (SACCO DOS ANJOS, 2001, p. 57).

Adiante, em meados dos anos 1980, a utilização do termo pluriatividade, como identificador de um fenômeno semelhante à agricultura de tempo parcial, começou a ser utilizado, refletindo, desta forma, alterações nos debates acerca dos rumos da agricultura, do desenvolvimento agrário e do papel da agricultura familiar. Ademais, a pluriatividade seria espécie de estratégia de ajustamento, ou seja, forma encontrada por algumas famílias rurais no sentido de enfrentar um contexto social adverso, marcado por incertezas (MACHADO; CASALINHO, 2010). Essa discussão inseria-se, nesta época e na Europa, no cerne de toda uma mutação no tratamento das questões voltadas à agricultura, sobretudo pelos governos de alguns países e pela Comissão Europeia.

Hervieu (1996), na obra Los campos del futuro, estimula a discussão acerca do futuro das populações rurais no século XXI. No documento acima nominado, desdobram-se elementos para a compreensão das transformações radicais das funções da agricultura no mundo rural francês e espanhol, bem como do entorno comunitário. Pôs-se em questão o modelo de desenvolvimento e as relações estabelecidas no pós-guerra que, aplicando recursos e esforços no meio urbano-industrial, provocaram alterações importantes no papel desempenhado pelas áreas rurais. Também foram postos em xeque os conceitos de agrário e rural, em apoio ao que viria a seguir: a tentativa de aniquilamento, supervisionada pelo Estado, dos camponeses e de sua agricultura familiar.

Embora o foco dos países europeus, é preciso levar em conta que muito do que foi dito e propalado naquele continente serviu e serve de modelo aos países subdesenvolvidos ou em desenvolvimento, vez que é parte de toda uma estratégia de destruição de uma classe social. Assim, para Hervieu (1996), haveria rupturas que seriam essenciais para explicar a crise da agricultura e do mundo rural. Primeiramente, a tomada de consciência dos agricultores de que se constituem, na sociedade moderna, em 


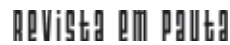

\} PLURIATIVIDADE NO MEIO RURAL - WERLANG, R.; MENDES, J. M. R. \}

DOI: $10.12957 /$ REP.2016.27857

uma minoria entre outras tantas. Só uma minoria da população rural francesa teria se transformado em população agrícola.

A segunda questão diz respeito ao esgotamento do paradigma da produção familiar. Aqui, abre-se a discussão acerca do processo de assalariamento das mulheres do campo, das esposas dos agricultores, afirmandose que o rural não é mais o mesmo. Além disso, o rural é tido como um território desenraizado, extirpado, com mobilidade de atividades produtivas e tendência à concentração e especialização das atividades produtivas.

O documento também questiona a tradicional função da agricultura no que se refere à produção de alimentos. Diz Hervieu (1996, p. 95): "El famoso slogan: nuestro oficio consiste en alimentar a la humanidade ya no funciona". Por fim, o autor ainda afirma que a agricultura seria responsável por preocupantes problemas ambientais que fariam o planeta padecer. A ideia seria pensar a agricultura de outro modo, destruir suas bases e preparar ideologicamente a mudança para novo avanço do capitalismo no campo, ampliando o seu poder de lucro.

Finalmente, o documento define as linhas mestras para uma nova política rural. Tais princípios trariam o fundamento de que, em primeiro lugar, deve-se produzir com qualidade para se produzir melhor. Diz ainda que seria fundamental a integração territorial, afirmando a diferença crescente entre desenvolvimento rural e agrário; e traz, por fim, a definição de um novo ofício para o homem do campo, "que va mucho más alla del rol tradicional del agricultor" (HERVIEU, 1996, p. 99). Ademais, o documento coloca abaixo alguns conceitos, arremetendo contra o camponês, a agricultura familiar, a alma camponesa, entre outros. A ideia é a de que o agricultor e o mundo rural não têm mais saída senão assimilar as orientações gerais da sociedade, e que a sua gestão não pode e nem deve se dar em separado do resto do espaço e da sociedade. Propõe um "contracto de sociedad" entre os agricultores, o mundo rural e a sociedade inteira, buscando novas funções econômicas, territoriais e sociais para a agricultura.

Talvez essa seja a história da destruição do camponês e da agricultura familiar planejada e incitada pelos governos dos países desenvolvidos, primeiramente. É a morte planejada, a possibilidade da destruição completa. Ao se engajar em um trabalho fora de sua unidade de produção, mantendo-se vinculado à terra em regime de pluriatividade, a família toda sofre, vez que estão, de forma lenta e gradual, se despojando dos laços que os ligam à terra e aos meios de produção. "É uma expropriação lenta, inicialmente dos meios de produção, e, mais tarde da expropriação completa com a venda da terra" (MACHADO; CASALINHO, 2010, p. 72).

Portanto, pode-se dizer que a pluriatividade constitui-se em uma forma de acentuação da exploração capitalista nos interstícios da vida rural. Isto porque faz parte de um conjunto de transformações em curso que apontam para a flexibilização e a precarização das relações de trabalho, bem como para a reestruturação produtiva. Os efeitos incluem o aumento 


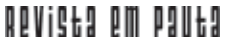

\} PLURIATIVIDADE NO MEIO RURAL - WERLANG, R.; MENDES, J. M. R. \}

DOI: $10.12957 /$ REP.2016.27857

da exploração do trabalho e a ampliação da margem de lucro por parte dos capitalistas (ALENTEJANO, 1999).

A pluriatividade pode, assim, ser definida como a combinação de atividades agrícolas e não agrícolas no interior da propriedade rural. Para Schneider (2013), as pesquisas sobre a questão envolvendo a pluriatividade no Brasil seriam ainda recentes e os primeiros estudos sobre a combinação de atividades agrícolas e não agrícolas no Brasil teriam começado tratando das formas complementares de trabalho e renda. Isto porque, em algumas regiões do país, os membros das famílias de pequenos agricultores eram levados à busca de trabalho e da ampliação de sua renda fora da propriedade rural, configurando-se em dupla ocupação. Posteriormente, de acordo com Schneider (1994), entraram em cena algumas noções importantes na análise da pluriatividade: part-time farming e multiple-job holding, já utilizadas na Europa e em outros países desenvolvidos. Tais noções teriam possibilitado dar conta de parcela significativa da população rural que estava dedicando apenas uma parte do seu tempo às atividades necessariamente agrícolas.

Por fim, a partir dos anos 1990 até a atualidade, desenvolve-se a noção de pluriatividade, entendida como elemento de diversificação; uma estratégia produzida no interior da unidade familiar ou mesmo a partir de seu exterior. Funcionaria como espécie de estratégia que se altera de acordo com a dinâmica das famílias e, ademais, com a relação das famílias e a estrutura agrária (SCHNEIDER, 1994). De toda sorte, pode-se dizer que se encontra em curso a expansão de atividades não necessariamente agrícolas no meio rural (SCHNEIDER, 2004).

A conciliação de atividades agrícolas e não agrícolas e as formas de trabalho assalariadas caracterizadas como urbano-industriais cada vez mais passam a fazer parte do "mundo rural", alterando sua estrutura econômica e social. O exercício de atividades remuneradas fora da propriedade rural por membros da família passa a constituir-se em realidade, transformando a estrutura do espaço que sempre se denominou rural em função das atividades ali desenvolvidas: o trabalho com a terra e a criação de animais.

Desse modo, é a partir da década de 1970 que começa a ser observado um processo de diferenciação no campo atribuído às transformações tecnológicas e às formas de reprodução da agricultura familiar em algumas regiões do Estado. Enquanto determinadas regiões se tecnificaram e se especializaram, outras, dedicadas à produção agrícola familiar, estagnaram e, de forma lenta, o sistema produtivo familiar foi sendo desarticulado pela emergência da part-time farming e da pluriatividade (SCHNEIDER, 2004). Outras estratégias de reprodução da agricultura também se desenvolveram, causando impactos.

"A seletividade do processo de modernização da agricultura e as distorções sociais dela decorrentes, como a expulsão de milhares de 


\section{hevistg an pguttg}

\} PLURIATIVIDADE NO MEIO RURAL - WERLANG, R.; MENDES, J. M. R. \}

DOI: $10.12957 /$ REP.2016.27857

pequenos agricultores do campo, alteraram, sobremaneira, o modo de vida das populações rurais" (SCHNEIDER, 2004, p. 86). As facilidades no transporte e a proximidade entre os pequenos agricultores e as indústrias que vão se instalando em locais mais próximos do rural permitiram a combinação do trabalho agrícola com o não agrícola. Ou seja, o rural é também local de vínculo com a indústria, não apenas através da produção, que naturalmente tem sido entregue a ela para fins de transformação, mas cada vez mais o pequeno agricultor, para conseguir viver, tem-se utilizado do expediente do trabalho fora da agricultura. Assim, o assalariamento constitui-se em uma estratégia às dificuldades enfrentadas pelos colonos, visando à própria sobrevivência. Neste sentido, há a possibilidade de se obter ganhos fora da propriedade, tornando possível viver e continuar vivendo na propriedade rural, plantando e consumindo os produtos básicos que a pequena agricultura torna possível.

Deste modo, essa nova forma de garantir renda transformou a estrutura produtiva familiar de várias regiões do Estado, e o conjunto dessas alterações transformou, por seu turno, a própria caracterização da agricultura familiar, que paulatinamente assume traços de uma pluriatividade. A principal característica desta forma de trabalho seria a dissociação de alguns membros da família rural do trabalho agrícola no interior da propriedade. Assim, a busca de atividades não agrícolas constitui-se, cada vez mais, em uma estratégia para a obtenção de renda (SCHNEIDER, 2004). É assim que a pluriatividade, ou a part-time farming, vai ganhando contornos e alterando a configuração do rural.

Assim como a entendemos, a pluriatividade que ocorre no meio rural refere-se a um fenômeno que pressupõem a combinação de pelo menos duas atividades, sendo uma delas a agricultura. Estas atividades são exercidas por indivíduos que pertencem a um grupo doméstico ligado por laços de parentesco e consangüinidade (filiação) entre si, podendo a ele pertencer, eventualmente, outros membros não consangüíneos (adoção), que compartilham entre si um mesmo espaço de moradia e trabalho (não necessariamente em um mesmo alojamento ou habitação) e se identificam como uma família. (SCHNEIDER, 2013, p. 3).

Entre os fatores que podem estimular a pluriatividade, o autor supracitado destaca os seguintes: a própria modernização técnico-produtiva da agricultura, uma vez que os processos de trabalho se tornaram mais individualizados, gerando redução significativa dos ativos rurais, ou seja, da própria mão de obra existente no núcleo das famílias. A razão para isso seria o intenso processo de modernização tecnológica das atividades agropecuárias, bem como a crescente externalização das etapas de produção.

Outro fator seria a terceirização e o crescimento da prestação de serviços no meio rural. Neste sentido, encontrar-se-iam em crescimento a 


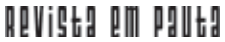

\} PLURIATIVIDADE NO MEIO RURAL - WERLANG, R.; MENDES, J. M. R. \}

DOI: $10.12957 /$ REP.2016.27857

subcontratação ou o aluguel de máquinas e equipamentos e, cresceria, ainda, a contratação de serviços de terceiros para a execução de tarefas antes realizadas no interior da propriedade.

O terceiro fator importante e incentivador da pluriatividade é a queda crescente das rendas provenientes da agropecuária. Uma vez inserida em padrões internacionais, os agricultores tendem a sofrer os efeitos da dependência tecnológica, implicando no aumento efetivo dos custos relativos à produção agrícola. De acordo com Schneider (2013), os agricultores seriam compelidos a acompanhar de forma incessante os avanços dos índices de produtividade da terra e do trabalho, potencialmente através do incremento do capital imobilizado, maquinários e benfeitorias, e pelo aumento da utilização dos insumos industriais, como os defensivos, combustíveis etc.

O quarto fator apontado pelo autor como estímulo à pluriatividade relaciona-se às mudanças nos mercados de trabalho. Tais mudanças teriam origem no processo de descentralização das indústrias, como já referido, que migraram para espaços antes considerados estritamente rurais, resultando em impactos à geração de empregos.

Em quinto lugar, podem-se evocar as políticas de desenvolvimento rural que têm estimulado o surgimento de atividades não agrícolas neste meio, tais como o turismo, as pequenas e médias indústrias, a preservação ambiental, entre outras. Essas políticas, que seriam mais comuns nos países desenvolvidos, teriam como objetivo buscar alternativas ao abandono em que se encontram algumas áreas rurais, bem como à redução dos impactos ambientais causados pelas formas intensivas de produção agrícola. $\mathrm{O}$ objetivo, assim, é gerar empregos, estimular a diversificação das rendas e oferecer alternativas econômicas aos pequenos agricultores, visando não ao aumento da produção agrícola de maneira geral, mas que estes possam oxigenar as atividades com novas práticas não agrícolas às regiões pouco competitivas nesses termos.

Por fim, Schneider (2013) aponta que a pluriatividade seria característica intrínseca à agricultura familiar, uma vez que várias atividades exercidas na mesma unidade familiar não seriam, necessariamente, um sinal de fraqueza ou definhamento da própria agricultura familiar. Podem ser, porém, um modo de funcionamento dessas unidades que se organizam em torno do trabalho da família na terra e tendem à diversificação. Neste sentido, a pluriatividade passou a ser percebida como uma estratégia de reprodução da agricultura familiar frente à ofensiva do capital e de adaptação ou sobrevivência às transformações econômicas que a agricultura familiar vem sofrendo.

Em que pese à pluriatividade constituir-se em alternativa à complementação da renda familiar, ela traz, em seu bojo, sua própria contradição. Ou seja, a de que as ocupações ou as atividades não agrícolas exercidas em meio rural pelo chefe da família ou pelos membros da família, ao 


\section{hevistg an pguttg}

\} PLURIATIVIDADE NO MEIO RURAL - WERLANG, R.; MENDES, J. M. R. \}

DOI: $10.12957 /$ REP.2016.27857

mesmo tempo em que podem ser vistas como estratégias de sobrevivência, indicam também a perda progressiva da condição e da identidade do agricultor (LOPES, 2013). Ademais, as atividades não agrícolas, não raro, são atividades de baixa qualificação e de baixa remuneração, existindo grandes diferenças conforme a região em que estas são exercidas. Para Lopes (2013), mais ao sul do país a pluriatividade tem um grande peso para a complementação de renda das famílias que se dedicam às atividades relativas à agricultura familiar.

Na Região Nordeste, tais atividades são consideradas precárias. $\mathrm{Na}$ análise da pluriatividade na região de Sergipe, por exemplo, Lopes (2013) conclui que a pluriatividade da agricultura familiar ali é bastante significativa, pois mais da metade das famílias (53\%) analisadas eram constituídas por agricultores pluriativos. No entanto, as atividades não agrícolas eram geralmente ocupações de baixa qualificação (pedreiro, ambulante, pintor), no caso dos autônomos ou de empregados no setor público (merendeira, professor, servente, vigilante, motorista), e de baixa remuneração.

Como visto, a pluriatividade pode ter um papel decisivo na promoção do desenvolvimento rural sustentável, colocando-se como alternativa às populações rurais através da geração de emprego, da melhoria da renda familiar, da redução da vulnerabilidade social e produtiva e do êxodo dos membros mais jovens da unidade familiar. No entanto, torna-se imperioso refletir acerca deste novo elemento que entra em cena, percebendo as transformações que podem ser acarretadas nos modos de vida e nas relações sociais estabelecidas no espaço onde as famílias dos agricultores familiares se inserem.

Em verdade, o modelo de desenvolvimento ou de modernização da agricultura imprimiu à agricultura familiar mudanças significativas, na medida em que um grande número de famílias de pequenos agricultores perdeu ou está em vias de perder o seu papel na produção agrícola, relegando o espaço rural a um local apenas de moradia. De outro lado, tem-se aqueles pequenos agricultores que se integraram aos complexos agroindustriais, aliando um patrimônio imobilizado cada vez maior a menores níveis de organização de seu próprio processo produtivo (SCHNEIDER; MATTOS, 2006). É neste sentido que se pode abordar a questão envolvendo um processo de proletarização rural e mesmo do desaparecimento do pequeno agricultor ou camponês.

Essa questão da integração do pequeno agricultor à indústria ou às outras atividades diversas daquelas tidas como agrícolas pode ser relacionada ao processo de acumulação capitalista no campo: o pequeno produtor perde a função da produção de alimentos quando não inserido nesta articulação com a indústria ou com outra atividade (SCHNEIDER; MATTOS, 2006). Assim, pode-se dizer que ser pequeno agricultor, camponês ou agricultor familiar, e viver desse trabalho, não é uma tarefa fácil. As relações 


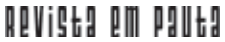

\} PLURIATIVIDADE NO MEIO RURAL -WERLANG, R.; MENDES, J. M. R. \}

DOI: $10.12957 /$ REP.2016.27857

econômicas e sociais que estão sendo estabelecidas no campo encontramse, sem sombra de dúvidas, submetidas às exigências do capital, porquanto a emergência da pluriatividade pode ser vista como uma forma de acentuação da exploração capitalista no campo, que flexibiliza e precariza as relações de trabalho visando à reestruturação produtiva: é preciso ampliar a margem de lucro e explorar cada vez mais o trabalho no mais longínquo dos espaços, sejam estes quais forem.

Destarte, pluriatividade constitui-se em espelho da exploração capitalista no campo, tornando-se expressão indelével dos tempos neoliberais. Estratégia do capital para continuar o seu processo de acumulação, abre fogo contra um espaço ótimo, um viveiro de mão de obra barata. Assim, a emergência da pluriatividade separa a produção da reprodução e aproxima a família, cada vez mais, a uma realidade de proletarização, cuja tendência seria a própria destruição enquanto unidade camponesa (MACHADO; CASALINHO, 2010).

Para além de se constituir em opção para o incremento da renda familiar, tal configuração é nociva no que condiz a tornar-se o trabalho agrícola apêndice do trabalho industrial ou, ainda, do trabalho não industrial precário e mal remunerado. Ademais, esta transformação adia, prejudica e protela toda a discussão acerca da Reforma Agrária, tão necessária no país.

\section{Considerações finais}

O processo de modernização que se deu na agricultura brasileira, de maneira geral, viabilizou-se por meio da tecnificação. Esta, por sua vez, implicou na quimificação e na mecanização da agricultura, alterando sua base técnica. A este contexto acrescente-se os incentivos à monocultura, especialmente aquela voltada à exportação, como é o caso da sojicultura. Ademais, tal processo ampliou sobremaneira a concentração da propriedade da terra, impedindo o acesso de significativas parcelas da população. Essa modernização capitalista avançou muito, de modo que tem alterado, por sua vez, o meio rural enquanto espaço de vida e de trabalho.

É com o avanço do capitalismo no campo que surgem os cenários de precarização e de flexibilização do trabalho; inscritos nestes, estão os mecanismos que levam à desintegração do campesinato, à sua aniquilação enquanto classe social. Tais mecanismos, como visto, são a articulação com a indústria e a pluriatividade. Para além de se constituírem em expressão da flexibilização e precarização do trabalho, são também vetores da destruição de uma economia com base na agricultura familiar. Entretanto, observase que tais mecanismos possuem duplo viés: são necessários enquanto meio de reprodução social, mas também são pérfidos, uma vez que atacam ou pervertem o pequeno agricultor na sua essência, qual seja, a produção da terra e a criação de animais para a sua sobrevivência e a de sua família. 


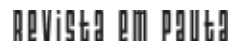

\} PLURIATIVIDADE NO MEIO RURAL - WERLANG, R.; MENDES, J. M. R.

DOI: $10.12957 /$ REP.2016.27857

É desta forma que se pode afirmar que cresce, nos interstícios da pequena agricultura familiar, um mundo rural cada vez mais "desruralizado". Neste espaço, o capital tem feito suas investidas, ampliando fronteiras e incitando o fim de modos de vida e trabalho tradicionais. Destarte, a acentuação da exploração capitalista no meio rural, pelas vias da pluriatividade e da articulação com a indústria, tem levado à proletarização do pequeno agricultor e à precarização do trabalho realizado, avalizando que o processo de modernização imprimiu à agricultura familiar mudanças que deixam os pequenos agricultores alheios ao seu papel originário na produção agrícola. 


\section{Referências}

ABRAMOVAY, R. (Org.) et al. Laços financeiros na luta contra a pobreza. São Paulo: Annablume, 2004.

. O futuro das regiões rurais. Porto Alegre: UFRGS, 2003.

ALENTEJANO, P. R. Pluriatividade: uma noção válida para a análise da realidade agrária brasileira? In: TEDESCO, J. C. (Org.). Agricultura familiar: realidades e perspectivas. Passo Fundo: UPF, 1999.

AMIN, S.; VERGOPOULUS, K. A questão agrária e o capitalismo. Rio de Janeiro: Paz e Terra, 1977.

ANDREATTA, T. et al. Origens da formação agrária sul rio-grandense no contexto brasileiro. In: 47ํㅡㄴ CONGRESSO DA SOCIEDADE BRASILEIRA DE ECONOMIA E SOCIOLOGIA RURAL (SOBER), Porto Alegre, 26-30 jul. 2009. Disponível em: <http://www.ufrgs.br/pgdr/arquivos/678.pdf>. Acesso em: 28 dez. 2012.

ARAÚJO, M. P. N. A questão camponesa na teoria marxista clássica. In: CHEVITARESE, A. L. (Org.). O campesinato na História. Rio de Janeiro: Relume Dumará, 2002.

CARDOSO, C. F. S. Camponês, campesinato: questões acadêmicas, questões políticas. In: CHEVITARESE, A. L. (Org.). O campesinato na História. Rio de Janeiro: Relume Dumará, 2002.

CAVALCANTE, D. Globalización y agricultura: las nuevas necessidades de la acumulación capitalista en el sector agrícola. In: HOUTARD, F. (Comp.). Quito, Equador: Universidad Andina Simón Bolívar, 2004.

FERNANDES FILHO, J. F.; CAMPOS, F. R. A indústria rural no Brasil. Revista de Economia e Sociologia Rural, v. 41, n. 4, nov./dez. 2003.

GRAZIANO DA SILVA, J. O novo rural brasileiro. Campinas: Unicamp, 2002.

HARDT, M. O trabalho afetivo. In: ROLNIK, S. et al. O reencantamento do concreto. São Paulo: Hucitec, 2003.

HARDT, M.; NEGRI, A. Multitud: guerra y democracia en la era del Imperio. Barcelona: Debate, 2004.

HERRERA FLORES, J. Los derechos humanos como productos culturales. Madrid: Catarata, 2005.

HERVIEU, B. Los campos del futuro. Madrid: Ministerio de Agricultura, Pesca y Alimentacion, 1996.

HOBSBAWM, E. A era dos extremos: o breve século XX (1914-1991). São Paulo: Companhia das Letras, 2000. 


\section{hevistg an pguttg}

\} PLURIATIVIDADE NO MEIO RURAL - WERLANG, R.; MENDES, J. M. R. \}

DOI: $10.12957 /$ REP.2016.27857

HOUTART, F. ¿Por qué los pequeños cultivadores de arroz deben desaparecer de Sri Lanka? In: AMIN, S. Las luchas campesinas e obreras frente a los desafíos del siglo XXI. Espanha: El Viejo Topo, 2005.

IANNI, O. Agricultura e mundialização. A pesquisa social na agricultura do sul do Brasil. Cadernos de sociologia, Porto Alegre: UFRGS, n. especial, 1994.

LÊNIN, V. I. U. Capitalismo e agricultura nos Estados Unidos da América: novos dados sobre as leis de desenvolvimento do capitalismo na agricultura. São Paulo: Editora Brasil Debates, 1980.

Cultural, 1985.

- O desenvolvimento do capitalismo na Rússia. São Paulo: Nova

LOPES, E. S. de A. A pluriatividade na agricultura familiar do Estado de Sergipe. [2013]. Disponível em: <http://www.fundaj.gov.br/geral/observa nordeste/eliano3.pdf>. Acesso em: 23 jan. 2013.

MACHADO, A. M. B.; CASALINHO, H. D. Crítica à pluriatividade e suas relações com o campesinato e a reforma agrária. Revista Nera, ano 13, n. 17, 2010.

MARX, K. O capital: crítica da economia política. V. 1. Rio de janeiro: Civilização Brasileira, 1980.

1986.

. Formações econômicas pré-capitalistas. Rio de Janeiro: Paz e Terra,

MAZOYER, M. Mundialización liberal y pobreza campesina: ¿qué alternativa? In: HOUTARD, F. (Comp.). Globalización, agricultura y pobreza. Quito, Ecuador: Ediciones Abya-Yala, 2004.

OLIVEIRA, A. U. Los mitos del agronegocio en Brasil. In: HOUTARD, F. (Comp.). Globalización, agricultura y pobreza. Quito, Ecuador: Ediciones Abya-Yala, 2004.

SACCO DOS ANJOS, F. S. dos. Pluriatividade e ruralidade: enigmas e falsos dilemas. Estudos, sociedade e agricultura, n. 17, out. 2001.

SANTOS,M ; SILVEIRA M.L. O Brasil: território e sociedade no início do século XXI. Rio de Janeiro: Record, 2004.

SCHNEIDER, S. O desenvolvimento agrícola e as transformações da estrutura agrária nos países do capitalismo avançado: a pluriatividade. Revista Reforma Agrária, ABRA, Campinas, v. 24, n. 3, 1994.

Agricultura familiar e industrialização: pluriatividade e descentralização industrial no Rio Grande do Sul. Porto Alegre: Editora da UFRGS, 2004. 
- A pluriatividade no meio rural brasileiro: características e perspectivas para investigação. [2013]. Disponível em: <http://www.ufrgs.br/ pgdr/arquivos/384.pdf>. Acesso em: 7 jan. 2013.

SCHNEIDER, S.; MATTOS, E. J. de. A pluriatividade no meio rural gaúcho: caracterização e desafios para o desenvolvimento rural sustentável. Extensão Rural e Desenvolvimento Sustentável, Porto Alegre, v. 2, n. 1/2, jan./ago. 2006. Disponível em: <http://www.emater.tche.br/site/br/arquivos/servicos/ biblioteca/publicacoes/vol2/n1_2/pag6.pdf>. Acesso em: 7 jan. 2006.

SOUZA FILHO, F. R. As transformações no espaço agrário sul-riograndense pós 60. Cadernos de Sociologia, Porto Alegre: PPGS, 1994.

SWAMINATHAN, S. Desafíos y luchas en agricultura de la India hoy. In: AMIN, S. Tres millones de campesinos amenazados. In: AMIN, S. (Org.). Las luchas campesinas y obreras frente a los desafios del siglo XXI: el porvenir de las sociedades campesinas y la reconstrución del frente unido de los trabajadores. Espanha: El Viejo Topo, 2005.

TEDESCO, J. C. O produtor familiar e a agroindústria. Cadernos de Sociologia, Porto Alegre: PPGS, n. 6, 1994.

WOLF, E. R. Los campesinos. Barcelona: Editorial Labor, 1971.

Recebido em 09 de julho de 2015.

Aprovado para publicação em 09 de agosto de 2016.

DOI: 10.12957/rep.2016.27857

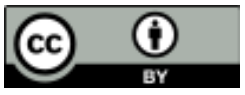

A Revista Em Pauta: Teoria Social e Realidade Contemporânea está licenciada com uma Licença Creative Commons Atribuição 4.0 Internacional. 